\title{
FEASIBILITY STUDY OF THE METHOD CHOICE OF MANUFACTURING SCREW CLEANING ELEMENTS WITH THE DEVELOPMENT AND USE OF SOFTWARE
}

\author{
Roman ROGATINSKIY*, Ivan HEVKO, Andriy GYPKA, Oksana GARMATYK, Sergiy MARTSENKO \\ Ternopil Ivan Puluj National Technical University, Ukraine
}

\begin{abstract}
A computer simulation of a curved profile formation on a helical spiral was carried out. A feasibility study was conducted in order to choose the method suitable for manufacturing of L-shaped helical spirals using specially developed software for calculating of the costs of helical spiral formation processes. The tables presenting technological characteristics of the design parameters of screw coiling working bodies manufactured by different methods are provided. The production costs for 1 meter of helical spiral with a curved profile manufactured by different methods are calculated. Theoretical and experimental investigations proved that the most cost-effective method of L-shaped helical spiral manufacturing is to coil it along the inner face from rectangular pieces with simultaneous or subsequent shelve formation.
\end{abstract}

Keywords: curved profile; feasibility study; manufacturing of L-shaped helical spirals

The creation and improvement of the designs of screw transport and technological mechanisms contribute to further economic development and improve the productivity.

L-shaped spiral augers (LSSA) are widely used in the constructions of transport and technological mechanisms, particularly in cleaning and transporting of augers, screw separators, descents, etc. Therefore, their production importance is indisputable. The considerable amount of scientific works is dedicated to the issues related to spiral auger production and its manufacturing (German, 1975; Hevko, 1986; Hevko et al., 2008; Pylypets, 2002; Gurvych, 1985; Vasylkiv et al., 2004; Danylchenko et al., 2002; Zhuravliov et al., 1980; Lysovoy, 1966; Hevko et al., 2015; Rorres, 2000; Ingaldi and Lestyánszka Škůrková, 2014). However, the challenge to develop advanced methods of L-shaped auger sub-type manufacturing is still relevant.

\section{Material and methods}

The objective is to substantiate the feasibility of the method choosing of manufacturing screw cleaning elements necessary for efficient purification of discs that dig the root crops. The digging process is accompanied by significant sticking of soil and chaff and grain heaps to the surfaces of disk diggers. Digging devices are often equipped with LSSAs, providing efficient cleaning of diggers' surfaces. In this regard, the challenge lies in studying the feasibility of method choosing for LSSA manufacturing that meet modern requirements for performance, economic efficiency, and material and energy consumption.

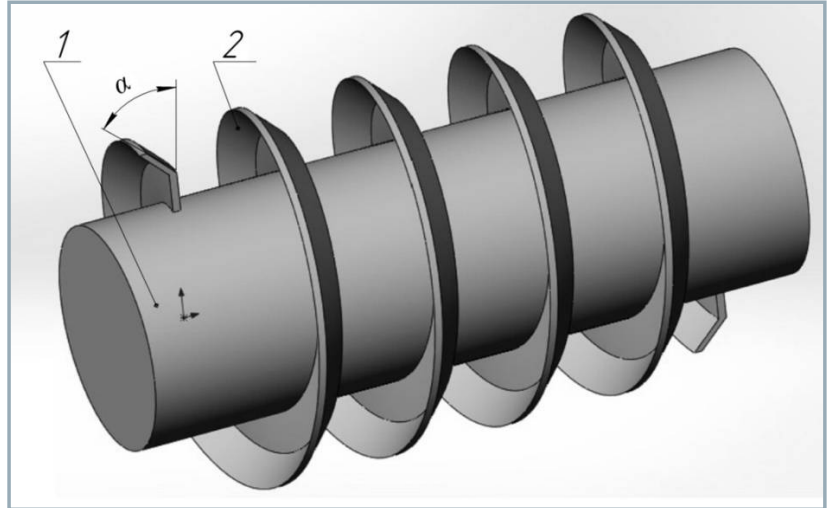

Fig. 1 Simulation of LSSA

1) axle; 2) spiral with a curved profile

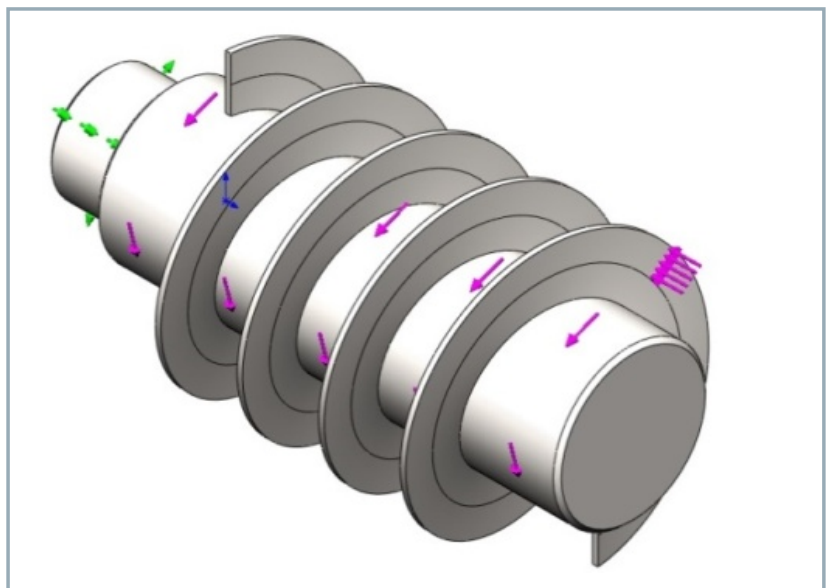

Fig. 2 Model of LSSA with applied shelve bending force $P_{2}$

Contact address: Roman Rogatinskiy, Ternopil Ivan Puluj National Technical University, Faculty of Engineering of Machines, Structures and Technologies, Ukraine, e-mail: rogatynskyi@gmail.com 


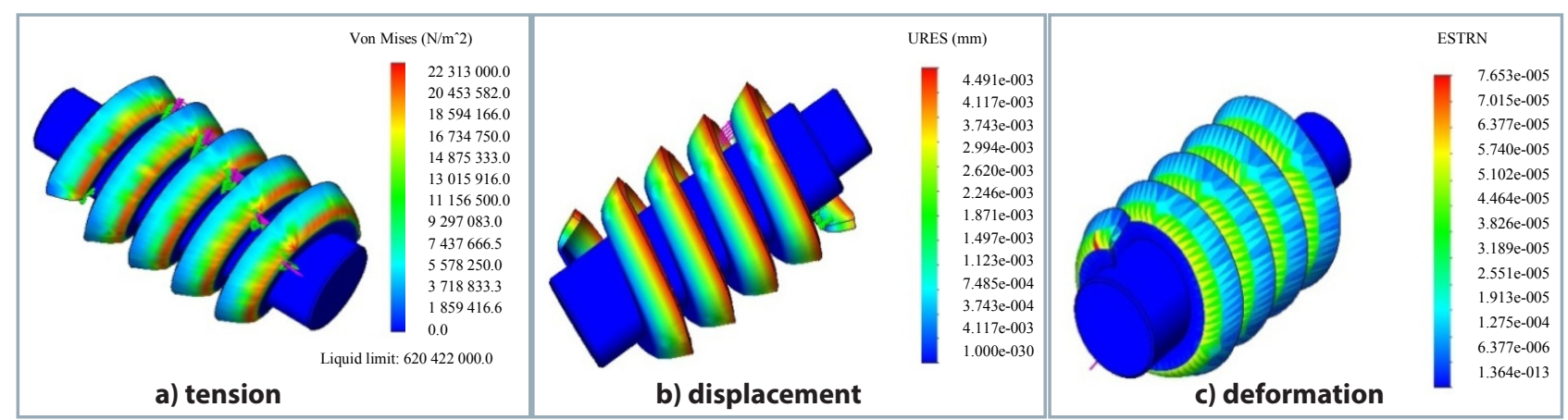

Fig. 3 Simulation of LSSA forming with determination of spiral

A computer model of LSSA was created by means of software package (Lyashuk et al., 2016). Its general view is shown in Fig. 1. In order to calculate the shelve inclination angle $\alpha$ and to develop the appropriate graphical dependencies on forces and torque, appropriate simulation was conducted (Fig. 2). The following parameters acted as variables: the shelve inclination angle $\alpha$; the screw spiral thickness $s$; shelve width $B$; and the material of a workpiece.

Graphical representation of LSSA element displacement (Fig. 3a), as well as LSSA element tension (Fig. 3b) and LSSA element deformation (Fig. 3c) under the applied bending force were also obtained by means of software.

Based on the data from computer simulation of a curved profile formation, the change dependencies of the shelve inclination angle on the spiral thickness $s$ and applied bending force $P_{\text {bend }}$ (Fig. 4) were developed. Therefore, the following conclusion should be made: if the thickness of a spiral turn and shelve inclination angle increase, the bending force also increases. The bending force grows more rapidly at the initial stage of the bending process and is slightly decreasing at the following stages.

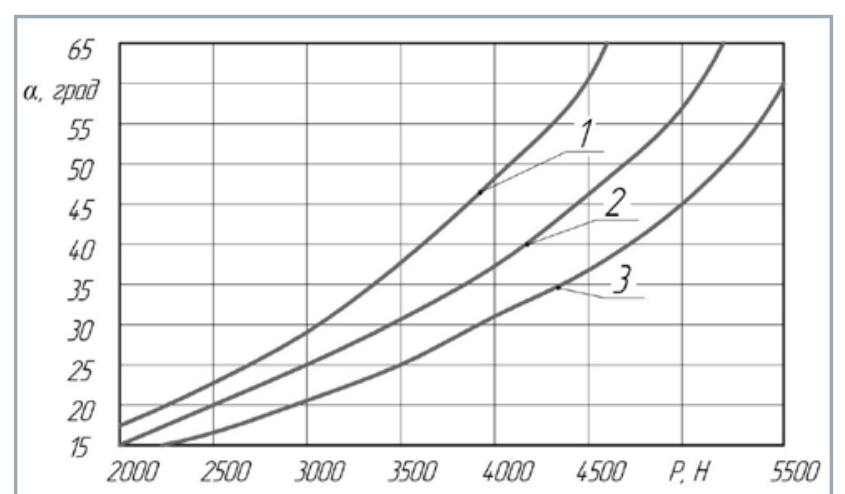

Fig. 4

Dependencies of the curved profile inclination angle $\alpha$ change on applied bending force $P_{\text {bend }}$ at spiral turn thickness $s: 1) 1 \mathrm{~mm}$; 2) $1.5 \mathrm{~mm}$; 3) $2 \mathrm{~mm}$.

Screw spirals can be of different designs and made of different materials (metals, plastics, rubbers, etc.). When calculating their final production cost, the cost of main and secondary materials, base and additional wages, as well as the cost of the energy for technological purposes and general production expenses should be taken into account. Their production cost directly depends on the type of production technology and can be roughly determined by the following formula (Hevko, 2013):

$$
\begin{aligned}
C= & k_{s e r} \cdot k_{s k}\left(k_{t-p} \cdot k_{d m} \cdot\left(\sum_{z=1}^{1} n_{z} \cdot C_{z}+\sum_{j=1}^{q} m_{j} \cdot C_{j}-\sum_{j=1}^{q} m_{v j} \cdot C_{v j}\right)+\right. \\
& \left.+\left(k_{d}+k_{z v}\right) \cdot\left(b_{1} \cdot \sum_{e=1}^{w} T_{e}+b_{2} \cdot T_{a s}\right)+k_{v e n} \cdot \sum_{j=1}^{q} m_{j} \cdot C_{j}\right)
\end{aligned}
$$

where:

$k_{\text {ser }}$ - serial coefficient that takes into account spiral production volumes (for single production $k_{\text {ser }}=$ 1.25-1.5; for serial production $k_{\text {ser }}=1.01-1.25$; for mass production $k_{\text {ser }}=1$ )

$k_{s k}$ - coefficient that takes into account the structural complexity of spiral manufacture $\left(k_{s k l}=1-1.5\right)$

$k_{t-p}$ - coefficient that takes into account transportation and procurement costs $\left(k_{t r}=1.05-1.15\right)$

$k_{d m}$ - coefficient that takes into account the cost of additional materials $\left(k_{d m}=1.01-1.02\right)$

I - number of component types used for spiral manufacturing

$n_{z}$ - number of $z^{\text {th }}$ component type used for the spiral manufacturing, pcs

$C_{z}$ - component price of $z^{\text {th }}$ type, $\mathrm{UAH}$

$q$ - amount of materials used for spiral manufacturing, pcs

$m_{j}$ - weight of material of the $j^{\text {th }}$ type used for spiral manufacturing, $\mathrm{kg}$

$C_{j}$ - cost of material of the $j^{\text {th }}$ type used for spiral manufacturing, UAH.

$m_{v j}$ - weight of material waste from the $j^{\text {th }}$ type, $\mathrm{kg}$

$C_{v j}$ - price of material waste from the $j^{\text {th }}$ type, UAH

$k_{\text {dopl }}$ - coefficient of additional payments $\left(k_{\text {dopl }}=1.25-1.3\right)$

$k_{z v}$ - coefficient that takes into account overhead costs in the manufacture of spiral $\left(k_{z v}=1.4-1.8\right)$

$b_{1}, b_{2}$-average hourly wage rate of core workers which are respectively engaged in spiral element manufacturing and assembly, UAH.

$w \quad$ - number of types of parts manufactured for a spiral

$T_{e} \quad$ - complexity of machining of the eth type of spiral parts, norm $\cdot \mathrm{hr}^{-1}$

$T_{a s}$ - complexity of assembling a spiral, norm $\cdot \mathrm{hr}^{-1}$

$k_{\text {ven }}$ - coefficient that takes into account the cost of energy for technological purposes in spiral manufacturing $\left(k_{\text {ven }}=1.05-1.2\right)$ 
Table 1 Dependence of spiral cost on production method

\begin{tabular}{|l||c|c|c|c|}
\hline \multirow{2}{*}{ No } & Method of spiral manufacturing & \multicolumn{3}{|c|}{ Type of production (expenses) } \\
\hline $\mathbf{1}$ & punching and spiral welding & unit & serial & mass \\
\hline $\mathbf{2}$ & spiral rolling & - & - & high \\
\hline $\mathbf{3}$ & spiral coiling & middle & low & low \\
\hline $\mathbf{4}$ & spiral production using flat blanks & middle & low & - \\
\hline $\mathbf{5}$ & sectional production using plastic & - & middle & low \\
\hline $\mathbf{6}$ & production of rubber elements & middle & low & low \\
\hline
\end{tabular}

A method of spiral manufacturing depends on the type of production, which significantly affects the spirals' cost (Table 1). To simplify the calculation of auger spiral production costs, the automated calculation software was developed. It introduces input data (manufacture program, spiral dimensions, workpiece material, and method of production) and gradually determines the type of production and the complexity of technological process. It defines the required number of workers belonging to different categories and calculates their wages and social contributions. It determines the material costs, calculates the cost of necessary equipment and the expenses for its maintenance and operation, as well as the craft and production cost of auger spiral manufactured by the specified method.

Comparing these methods, the cheapest version can be chosen. It is necessary to enter the following data for calculation: the given output program and the relevant design parameters. The software includes the following windows: characteristic of technological process options, the composition of technological equipment, summary of workers, capital expenditure on fixed assets, consolidated statement of annual payroll, estimated cost of materials, estimated workshop cost, cost of product manufacturing, cost of unit production, the main technical and economic indicators.

\section{Results and discussion}

The manufacturability of screw element designs should be tested by means of the rational selection of material blanks, output specification and production type, technological performance analysis of individual parts, and development of measures for their improvement. LSSAs are considered the original parts with high technological complexity and labour intensity of manufacturing. Their production differs from the modern production technology used for typical straight cylindrical spirals, since there is a need to create additional shelves at a certain angle (from $1^{\circ}$ to $120^{\circ}$ ). It requires the use or special equipment, or to perform additional manufacturing operations. To produce LSSA, it is necessary to consider, analyze and select the most effective way of its shaping (Table 2). It is possible to produce such spirals by stamping the rings with the following loop forming and welding. The cylindrical straight spiral can be produced by coiling or rolling, followed by the shelve welding at the desired angle (from $1^{\circ}$ to $120^{\circ}$ ). For this purpose, the different methods of coiling are applied: band blanks are coiled on the edge, and simultaneously, shelves are formed at a certain angle (from $1^{\circ}$ to $60^{\circ}$ ); band pieces are coiled on the edge, and subsequently, the shelves are formed at a certain angle (from $1^{\circ}$ to $90^{\circ}$ ) by means of bending operation; the profile of L-shaped pieces is coiled on the edge and shelves were previously formed at a certain angle (from $1^{\circ}$ to $90^{\circ}$ ). Coiling along the inner face profile from rectangular pieces with simultaneous or subsequent formation of shelves is the most rational method of LSSA production. It ensures a high utilization rate of material and eliminates the need for welding.

The possible methods for LSSA manufacturing were approximately calculated in order to compare and choose the most rational ones (spiral thickness $-2 \mathrm{~mm}$, coil height $25 \mathrm{~mm}$, outer diameter - $100 \mathrm{~mm}$, material - steel $08 \mathrm{kp}$ ). The production cost calculation results for $1 \mathrm{~m}$ of LSSA using different manufacturing methods are presented in Table 3.

It can be concluded that coiling along the inner face profile from rectangular blanks with simultaneous or subsequent shelve formation, as well as LSSA coiling on the edge with previous shelve shaping, are the most cost-effective ways of LSSA manufacturing. Such methods are approximately three times cheaper than the rest. Particularly, the LSSA manufacturing by punching rings with simultaneous or subsequent cutting, straightening and welding; the rolling

Table 2 Technological characteristics of design parameters of L-shaped helical spirals produced by different methods

\begin{tabular}{|l||c|c|}
\hline No & Method of formation & Utilization coefficient of material, K \\
\hline $\mathbf{1}$ & $\begin{array}{r}\text { ring punching of L-shaped profile with simultaneous or subsequent cutting, } \\
\text { straightening and welding }\end{array}$ & $0.4-0.5$ \\
\hline $\mathbf{2}$ & $\begin{array}{r}\text { coiling of L-shaped spirals along the profile inner face from rectangular blanks } \\
\text { with simultaneous or subsequent shelve formation }\end{array}$ & $0.9-1.0$ \\
\hline $\mathbf{3}$ & colling of a cylindrical straight spiral and further welding of shelves & $0.55-0.98$ \\
\hline $\mathbf{4}$ & coiling of L-shaped blanks on the edge with previous shelve shaping & $0.9-1.0$ \\
\hline $\mathbf{5}$ & & $0.9-1.0$ \\
\hline
\end{tabular}


Table 3 Production cost calculation results for $1 \mathrm{~m}$ of helical spiral with a curved profile using different manufacturing methods

\begin{tabular}{|l||c|c|c|c|c|}
\hline $\begin{array}{l}\text { Elements costs } \\
\text { (UAH) }\end{array}$ & $\begin{array}{c}\text { Method no 1 } \\
\text { from Table 2 }\end{array}$ & $\begin{array}{c}\text { Method no 2 } \\
\text { from Table 2 }\end{array}$ & $\begin{array}{c}\text { Method no 3 } \\
\text { from Table 2 }\end{array}$ & $\begin{array}{c}\text { Method no 4 } \\
\text { from Table 2 }\end{array}$ & $\begin{array}{c}\text { Method no 5 } \\
\text { from Table 2 }\end{array}$ \\
\hline Materials & 37.68 & 19.22 & 22.16 & 19.22 & 19.22 \\
\hline Salary & 9.23 & 0.29 & 9.2 & 9.32 & 0.36 \\
\hline $\begin{array}{l}\text { Social } \\
\text { contributions }\end{array}$ & 3.51 & 0.11 & 3.5 & 3.54 & 0.14 \\
\hline Energy & 1.97 & 0.1 & 2.37 & 2.02 & 0.16 \\
\hline Total expenditures & 16.78 & 0.53 & 16.73 & 16.95 & 0.65 \\
\hline Production cost & 69.17 & 20.25 & 53.96 & 51.05 & 20.53 \\
\hline
\end{tabular}

of cylindrical straight spiral and further welding of the shelves; the coiling of cylindrical straight spiral and further welding of shelves seems to be cost-ineffective.

To confirm the economic justification for the choice of LSSA manufacturing method, a complex experimental study was conducted using special technological processes and technological equipment (Figs. 5-8).

The technological process, the scheme of which is presented in Fig. 5, involves forming of a curved profile of stretched spirals with the appropriate step. There were three series of experiments (Fig. 6) using the auger frames with

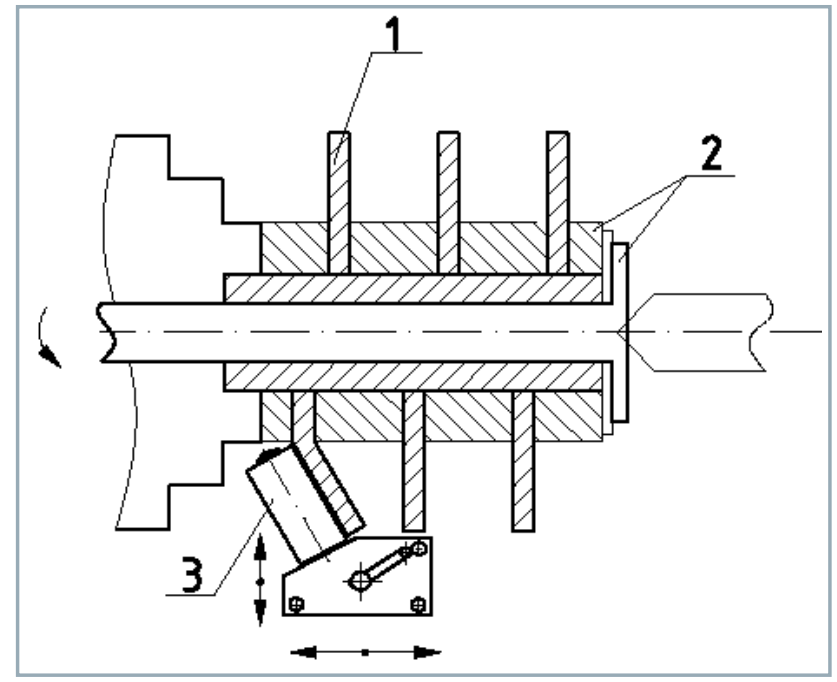

Fig. 5 Manufacturing process scheme of LSSA production

1 - spiral; 2 - spiral mounting; 3 -forming tool

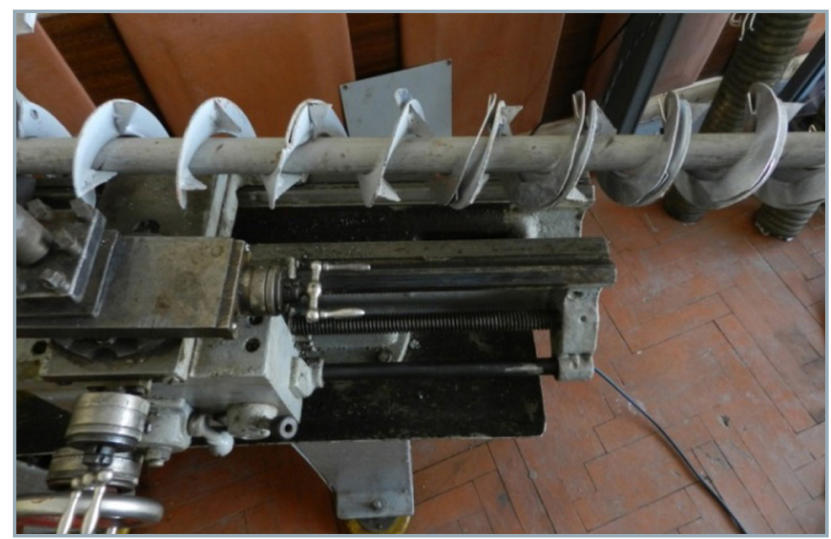

Fig. 6
Auger frame with installed screw workpiece an inner diameter of $50,55,60 \mathrm{~mm}$ and an outer diameter of $90,104,118 \mathrm{~mm}$. Strengthening ribs were welded on one side of the given auger frames in order to protect the helical spiral from deflection in the direction of forming. For

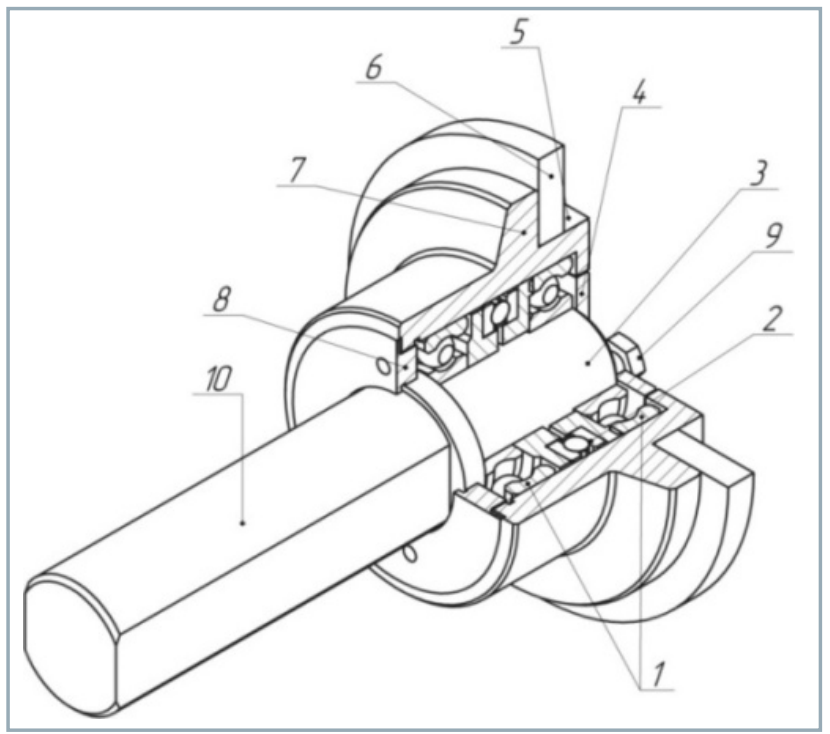

Fig. 7 Construction scheme of forming roller

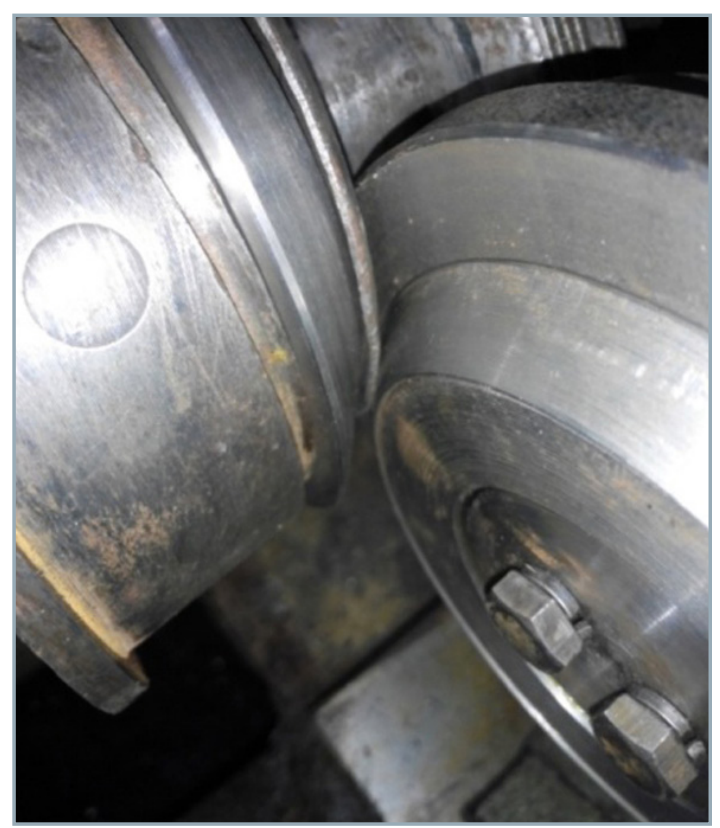

Fig. 8 LSSA production by forming tool 
manufacturing of LSSAs with spirals made of steel $08 \mathrm{kp}$, 20 Steel, 30 Steel, different experiments were conducted.

The technological process of the helical spiral curved profile forming by means of tight package and with a help of forming bushings, rings and roller with formative surface angles $\alpha$ about the spiral rotation axis $-15^{\circ}, 25^{\circ}, 35^{\circ}$ and the height of the strip vertical part - 10, 15, $20 \mathrm{~mm}$ was also developed and tested (Fig. 8). The further calibration of the blank with a specific step was performed during reverse motion of forming hub and the main motion of machine tool.

According to the methodology of experimental studies, the technological, power and design parameters of shelve bending processes of helix spiral should be defined. LSSAs were coiled on the lathes models $16 \mathrm{~K} 20,16 \mathrm{E} 16 \mathrm{KP}$ with previously defined spindle frequency within the range of: $\omega=1.0-1 \cdot 5^{\mathrm{c}-1}$. To start the main motion of the machine and to control its rotation speed, a frequency converter Altivar and software PowerSuite v.2.5.0 were used. Shelve bending force was measured using a frequency converter ALTIVAR 71, its data was sent to PC. The resulting changes in torque and engine power over time were obtained in the form of graphical and tabular dependencies in the display window of the computer.

Experimental research was conducted in order to define the dependence of bending force on spiral thickness, workpiece diameter and inclination angle of bushing shaping. The research results were implemented by planning and conducting the three-factor experiment (2) - (4). To obtain a regression model of optimization parameter in the form of complete quadratic polynomial, an appropriate plan of a full-factor experiment was developed. This plan was implemented in a well-known sequence. After experimental data processing, the regression equation was deduced in the following form:

- for the blank material (steel $08 \mathrm{kp}$ ):

$$
\begin{aligned}
M_{(08 \mathrm{kp})}= & 93.31-2.26 D-93 s+1.79 \alpha+0.99 D s-7 \cdot 10^{-3} D \alpha+ \\
& +0.55 s \alpha+0.012 D^{2}+3.76 s^{2}-0.029 \alpha^{2}
\end{aligned}
$$

- for the blank material (20 Steel):

$$
\begin{aligned}
& \quad M_{(\text {steel } 20)}=105.2-2.53 D-102.82 s+1.95 \alpha+1.09 D s- \\
& -7.71 \cdot 10^{-3} D \alpha+0.61 s \alpha+0.014 D^{2}+4.28 s^{2}-0.031 \alpha^{2}
\end{aligned}
$$

- for the blank material (30 Steel):

$$
\begin{aligned}
& M_{(\text {steel } 20)}=115.58-2.77 D-112.26 s+2.12 \alpha+1.19 D s- \\
& -8.43 \cdot 10^{-3} D \alpha+0.67 s \alpha+0.015 D^{2}+4.72 s^{2}-0.034 \alpha^{2}
\end{aligned}
$$

The resulting regression dependences can be used for determining the forming torque of a curved profile on a coiled spiral within parameters: $90 \mathrm{~mm} \leq D \leq 118 \mathrm{~mm}$; $15^{\circ} \leq \alpha \leq 35^{\circ} ; 1 \mathrm{~mm} \leq s \leq 2 \mathrm{~mm}$. According to the obtained regression equations, the response surfaces were developed. Their graphical presentations are shown in Fig. 9-11.

The screw spiral diameter $D$ and spiral thickness $s$ were proved to be the predominant factors for affecting the torque value. The shelve angle $\alpha$ slightly influences the power parameters of a curved profile formation. The changes in torque depending on the diameter of the screw

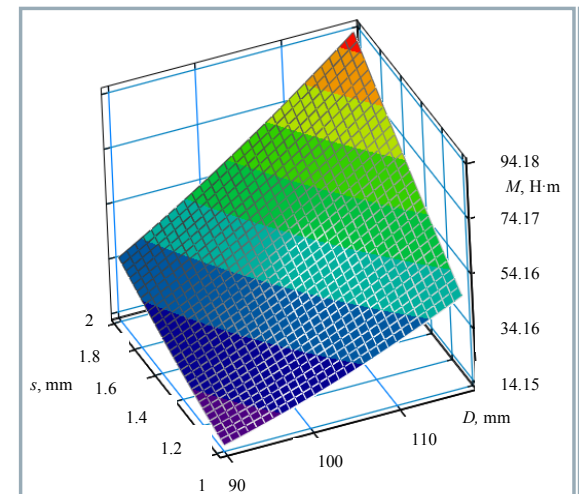

a) $\alpha=25^{\circ}$

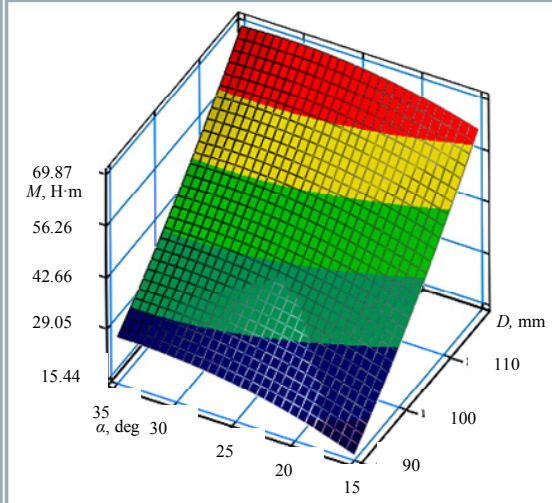

b) $s=1.5 \mathrm{~mm}$

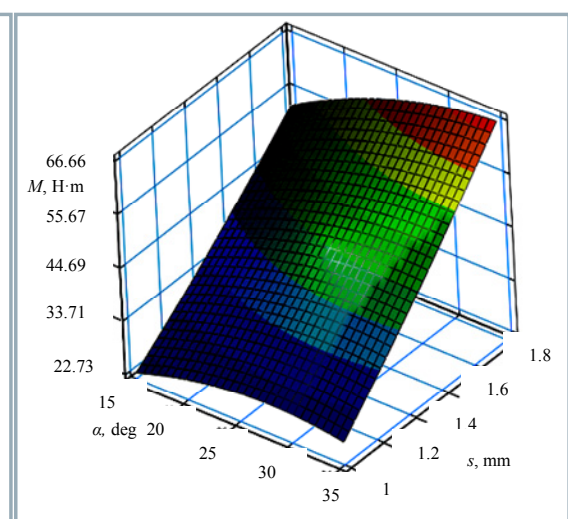

c) $D=104 \mathrm{~mm}$

Fig. 9 Response surface of torque dependence $M_{(D, s)}$ in the manufacture of shelves on a spiral made of steel $08 \mathrm{kp}$

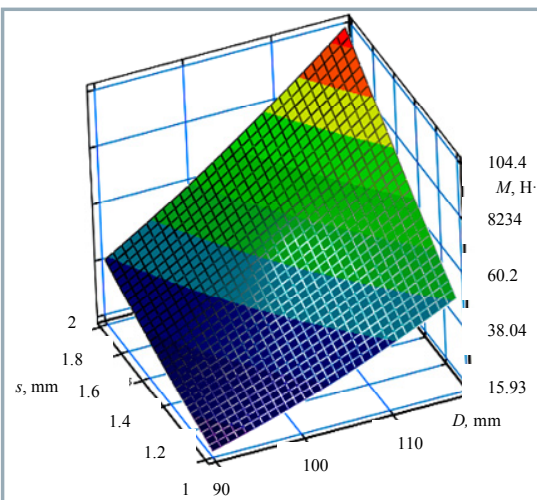

a) $\alpha=25^{\circ}$

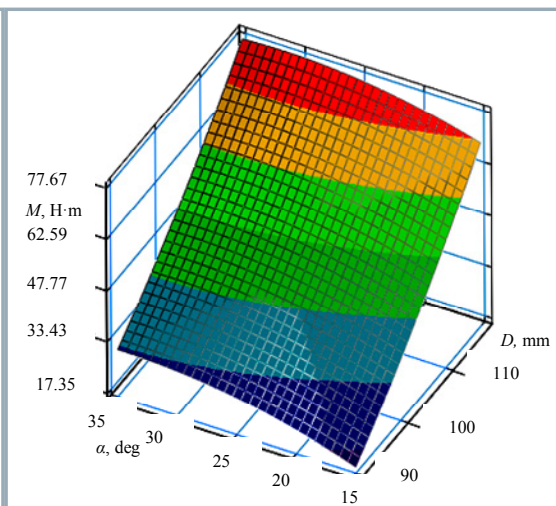

b) $s=1.5 \mathrm{~mm}$

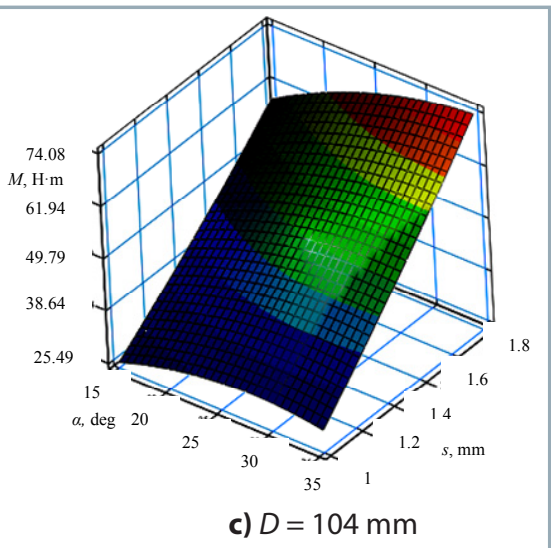

c) $D=104 \mathrm{~mm}$

Fig. 10 Response surface of torque dependence $M_{(D, s)}$ in the manufacture of shelves on a spiral made of Steel 20 


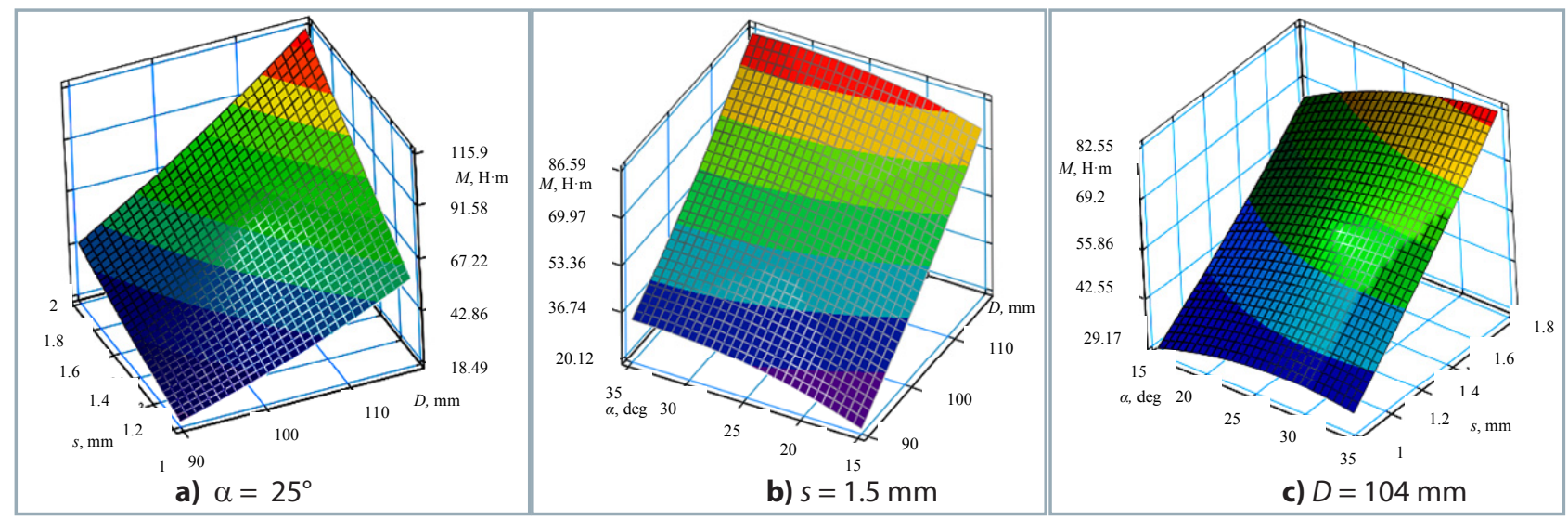

Fig. 11 Response surface of torque dependence $M(D, s)$ in the manufacture of shelves on a spiral made of Steel 30

spiral $D$ and spiral thickness are defined. They occur within the range of 14-94 $\mathrm{Nm}$ for Steel 08kp; within the range of 15-104 Nm for 20 Steel; and within the range of 18-115 Nm for 30 Steel with $\alpha=$ const.

According to experimental results, it is more efficient to form a curved profile of the screw blank by means of forming roller than by auger mandrel. The advantages of this method are: lower energy consumption; providing of even forming of a curved profile of the screw blank while ensuring the required accuracy of tilt angle $\alpha$; allowing for avoidance of corrugated curved profile of the screw blank; possibility to be used for shaping of the curved profile with a spiral thickness s over $3 \mathrm{~mm}$; significantly lower required amount of processing equipment, especially for curved profile shaping of the screw blank of different sizes.

The economic feasibility of the chosen LSSA manufacturing method was confirmed using the conducted complex experimental study. The manufacturing process of a curved profile formation of the screw blank was developed and improved.

\section{Conclusion}

Based on the data from a curved profile forming process computer simulation, it can be concluded that the bending force increases when the thickness of the spiral and the shelve inclination angle also increase. More rapid growth of bending force occurs at the initial stage of the process and is slightly decreasing at the further stages.

Based on technical and economic calculations of possible LSSA manufacturing methods, it was investigated that the most effective forming method of a curved profile of the screw spiral is to coil it along the profile inner face from rectangular blanks with simultaneous or subsequent shelve formation.

It was experimentally proved that the developed LSSA manufacturing technology by means of forming bushing, compared with the use of auger mandrel, has several advantages. In particular, its energy consumption is lower. It provides forming a curved profile of the screw blank while ensuring the required accuracy of tilt angle $\alpha$. It avoids corrugated curved profile of the screw blank and can be used for shaping of the curved profile with spiral thickness $s$ from $3 \mathrm{~mm}$ to $5 \mathrm{~mm}$. It requires significantly lower amount of processing equipment, especially for curved profile shaping of the screw blank of different sizes.

\section{References}

DANYLCHENKO, L. M. - HEVKO, I. B. - DRAGAN A.P. 2002. Investigation of stress-strain state in the process of forming curved pieces of screw profiles. In Mechanical Engineering: Scientific Notes, vol. 10, pp. 49-57.

GERMAN, H. 1975. Auger Mechanism in the Technologies of Germany. In Mechanical Engineering, 230 pp.

GURVYCH, V. Y. 1985. Development, parameter definition and introduction into production of cold forge-rolling of agricultural machines auger spirals. Abstract of dissertation for the Candidate degree (Engineering) in the field of Machining Processes, $20 \mathrm{pp}$.

HEVKO, B. M. - HEVKO, Iv. B. - RADYK, D. L. 2006. Agricultural Engineering Technology: teach. guidance. Kiev : Kondor, 496 pp. HEVKO, B. M. - LYASHUK, O. L. - HEVKO, Iv. B. 2008. Technological Backgrounds of Forming Special Screw Profile Details. Ternopil :TDTU named after Ivan Pul'uj, $367 \mathrm{pp}$.

HEVKO, IV.B. - DYCHUN, A.Y. - LYASHUK, O.L. - MARTSENKO, S. GYPKA, A.B. 2016. Research the force parameters of forming the screw cleaning elements / INMATEH «Agricultural Engineering, vol. 49, no. 2. pp. 77-83.

HEVKO, I. B. 2013. Scientific and applied backgrounds for manufacturing screw transportation and technological mechanisms. In Abstract of dissertation for the Doctor degree (Engineering) in the field of Engineering, Lviv, $42 \mathrm{pp}$.

INGALDI, M. - LESTYÁNSZKA ŠKU゚RKOVÁ, K. 2014. Technological level of machines in production process of screws. In Acta Technologica Agriculturae, vol. 17, no. 4, pp. 101-104.

LYASHUK, O. - SOKIL, M. - KLENDIY, V. - SKYBA, O. - DMYTRENKO, V. 2016. The study on nonlinear model of dynamics of a system 'extruder elastic auger working body'. In Acta Technologica Agriculturae, vol. 19, no. 4, pp. 102-107.

LYSOVOY, M. N. 1966. Theory and Calculation of the Processes of Manufacturing Parts by Bending Methods. Moscow : Mechanical Engineering, $236 \mathrm{pp}$.

PYLYPETS, M. I. 2002. Scientific and technological backgrounds of manufacturing coiled workpieces of machine parts: Extended abstract of dissertation for the Doctor degree in the field of Processes of Machining, Machine Tools and Instruments, Lviv, 35 pp.

RORRES, CH. 2000. The turn of the screw: Optimal design of an Archimedes screw. In Journal of Hydraulic Engineering, pp. 72-80.

VASYLKIV, V. V. - RADYK, L. D. - HEVKO, Iv. B. 2004. Technological and design features of making spiral pieces of sheet products. Interuniversity collection. In Mechanical Engineering : Scientific Notes of LSTU, vol. 14, pp. 12-18.

ZHURAVLIOV, A. Z. - VERZILOV, Y. N. - YEGOROV, V. A. 1980. Manufacture of Augers for Combine Harvesters. Moscow, pp. 29-31. 